\title{
Infecção Assintomática do Líquido Amniótico
}

\author{
Asymptomatic Amniotic Fluid Infection
}

Roxeane Martins Monteiro, Carlos Augusto Alencar Júnior, Francisco das Chagas Oliveira Cibele Barreto Mano de Carvalho, José Luciano Bezerra Moreira

\begin{abstract}
RESUMO
Objetivo: determinar a presença de infecção assintomática do líquido amniótico em gestantes, identificar os agentes bacterianos envolvidos na infecção e determinar o perfil de suscetibilidade a antimicrobianos in vitro.

Métodos: foram obtidas 81 amostras de líquido amniótico, colhidas por amniocentese, em gestantes sem sinais de trabalho de parto e sem suspeita clinica de infecção, atendidas na Maternidade Escola Assis Chateaubriand, entre agosto/97 e janeiro/99. Pesquisou-se a presença de bactérias aeróbias, anaeróbias estritas/facultativas e micoplasmas genitais. As bactérias anaeróbias foram identificadas pelo sistema ATB $^{\circledR}$ (Bio-Mérieux) e os micoplasmas pelo kit Micoplasmas IST ${ }^{\circledR}$ (Bio-Mérieux).

Resultados: entre as amostras obtidas, oito (9,8\%) apresentaram culturas positivas, sendo que em duas foram identificadas duas espécies bacterianas. Os patógenos isolados foram: Ureaplasma urealyticum (7 casos, 8,6\%), Mycoplasma hominis (1 caso, 1,2\%) $e$ Peptostreptococcus sp (2 casos 2,4\%). O padrão de resistência aos antimicrobianos caracterizou-se pela maior resistência dos micoplasmas à eritromicina $(37,5 \%)$ e nenhuma resistência às ciclinas.

Conclusões: o percentual de infecções assintomáticas foi muito elevado, havendo necessidade de serem realizadas novas pesquisas para avaliar as conseqüências da infecção subclínica nas grávidas e em seus conceptos, que envolvam métodos que identifiquem micoplasmas genitais, já que foram as bactérias mais freqüentemente isoladas.
\end{abstract}

PALAVRAS-CHAVE: Líquido amniótico. Corioamnionite. Infecções na gravidez.

\section{Introdução}

A gravidez é o estágio para qual o organismo feminino foi preparado e adaptado ao longo da evolução. O parto é o episódio resolutivo do ciclo puerperal e, em condições normais, ocorre após a $37^{\mathrm{a}}$ semana de gestação, sendo chamado de parto a termo. Se o feto nasce antes, trata-se de parto prematuro ou pré-termo ${ }^{1}$. Esta condição continua sendo um dos grandes problemas da obstetrícia, principalmente porque tem como uma de suas conseqüências a elevada mortalidade neonatal. A invasão microbiana do líquido amniótico tem sido

Maternidade Escola Assis Chateaubriand - Universidade Federal do Ceará

Departamento de Patologia e Medicina Legal

Correspondência:

Roxeane Martins Monteiro

Av. da Universidade, 3264, apto. 1002 bloco II - Bairro Benfica

60020-181 - Fortaleza - Ceará

Fone: (85) 9171-9564

e-mail-rox@secrel.com.br implicada como causa do parto prematuro, principalmente em pacientes com rotura prematura de membranas.

A etiopatogenia do parto prematuro e do rompimento prematuro de membranas parece ser multifatorial ${ }^{3}$. Muitas informações epidemiológicas, clínicas e laboratoriais relacionaram infecção e resposta inflamatória do trato reprodutivo como causas de trabalho de parto prematuro, rotura prematura de membranas e nascimentos pré-termo durante a gravide $z^{4}$.

Pacientes em trabalho de parto prematuro idiopático freqüentemente apresentam uma ou mais das seguintes características: evidência histológica de corioamnionite ${ }^{4}$; microrganismos nas membranas fetais, placenta ou líquido amniótico; endotoxinas bacterianas ou mediadores inflamatórios no liquido amniótico ${ }^{5}$.

A infecção subclínica do trato genital, provocada pela microbiota vaginal, estaria associada ao parto prematuro e à amniorrexe prematu- 
ra, em virtude da interação cumulativa entre os microrganismos e o hospedeiro ${ }^{3,4}$. Observou-se, por exemplo, que espécies bacterianas como $E$. coli e S. agalactiae aderiam à membrana corioamniótica e elaboravam enzimas como proteases e fosfolipases, que enfraqueciam as membranas fetais, ativando prostaglandinas e levando ao rompimento prematuro das membranas fetais ${ }^{6}$.

As fosfolipases $\mathrm{A}_{2}$ e $\mathrm{C}$, produzidas pelas bactérias existentes nas corioamnionites, estão presentes, também, na membrana corioamniótica, sendo liberadas em resposta à invasão bacteriana. A partir daî, são ativadas as prostaglandinas $\mathrm{F}_{2} \alpha$ e $\mathrm{E}_{2}$, estimulando contrações. Além disso, outros produtos, como leucotrienos e tromboxanas, atuam causando necrose focal. Estas reações locais enfraquecem as membranas, predispondo-as ao rompimento prematuro e ao parto pré-termo ${ }^{7}$.

Bobitt et al. ${ }^{8}$, em estudo realizado com 31 gestantes em trabalho de parto prematuro e membranas intactas, obtiveram 8 cultivos positivos do liquido amniótico, sendo que apenas duas pacientes apresentaram sinais clínicos de infecção.

Garite et al. ${ }^{9}$, comparando o resultado de 404 culturas do líquido aminiótico obtido por amniocentese, em pacientes com membranas rotas ou intactas, observaram $27,9 \%$ de positividade quando havia amniorrexe prematura. Com membranas integras o percentual foi de $16,1 \%$.

Romero et al. ${ }^{10}$, avaliando a existência de invasão microbiana na cavidade amniótica em partos a termo ou prematuros, com membranas intactas, obtiveram culturas positivas em 18,8\% e $21,6 \%$ dos casos, respectivamente. As bactérias mais freqüentemente isoladas foram: Ureaplasma urealyticum, Mycoplasma hominis, Streptococcus agalactiae e espécies de Lactobacillus. O mesmo pesquisador, em outro trabalho ${ }^{11}$, visando o diagnóstico clínico precoce de infecções intraamnióticas, detectou bactérias em apenas $12 \%$ das amostras de liquido. Isto ocorreu porque o desenvolvimento de sinais clínicos e sintomas de infecção podem ser tardios, relacionando-se com muitos fatores, incluindo o tamanho do inóculo, virulência do microrganismo, grau de resposta inflamatória materno-fetal e propriedades antibacterianas do líquido amniótico ${ }^{12,13}$.

O objetivo deste trabalho foi determinar o percentual de infecção assintomática intrauterina em gestantes sem suspeita clínica ou obstétrica de infecção, submetidas à amniocentese por outras indicações, identificando os agentes bacterianos envolvidos e o perfil de resistência a antimicrobianos in vitro.

\section{Pacientes e Métodos}

Este trabalho foi realizado prospectivamente no período entre 2 de setembro de 1997 e 18 de janeiro de 1999.

O grupo de estudo consistiu de 81 grávidas submetidas à amniocentese no intervalo entre a $14^{\mathrm{a}}$ e a $40^{\mathrm{a}}$ semanas de gravidez. As indicações para realização do procedimento foram a pesquisa da maturidade fetal em pacientes com indicação da resolução de gestação, a análise cromossômica do concepto e a avaliação da bilirrubina presente no líquido amniótico em gestantes com isoimunização pelo fator Rh. Não existiam sinais clínicos e/ou laboratoriais de infecção intra-uterina. O uso de antibióticos ou a suspeita de infecção intraútero no momento da coleta foram critérios para exclusão na pesquisa.

A maioria das pacientes foi submetida ao procedimento enquanto internada na Enfermaria de Patologia Obstétrica da Maternidade Escola Assis Chateaubriand (MEAC) da Universidade Federal do Ceará (UFC). Foram informadas, verbalmente e por escrito, sobre o trabalho e o consentimento foi obtido de cada uma delas. O projeto foi aprovado pelo Comitê de Ética em Pesquisa da UFC.

Para realização da amniocentese a grávida foi colocada em decúbito dorsal, realizada assepsia e, sob controle ultra-sonográfico, após anestesia local, introduziu-se agulha $20 \mathrm{G}$, de 9 ou $16 \mathrm{~cm}$ de acordo com a localização da coleção de fluido a ser obtida. O primeiro $\mathrm{mL}$ de líquido amniótico foi colhido em seringa própria e desprezado. A seguir, amostras de 10 a $20 \mathrm{~mL}$ foram obtidas e transportadas em seringas plásticas encapadas para o Laboratório de Microbiologia Médica do Departamento de Patologia e Medicina Legal da UFC. A amostra foi semeada imediatamente após a coleta e cultivada em aerobiose, microaerofilia e anaerobiose, incubada em estufa bacteriológica à temperatura de 35 a $37^{\circ} \mathrm{C}$, segundo Koneman et al. ${ }^{14}$. Além disso, foram realizadas culturas para micoplasmas genitais.

Nas culturas positivas, a identificação das espécies bacterianas e os antibiogramas foram feitos pelo sistema ATB Expression ${ }^{\circledR}$ (Bio-Mérieux). Para cultivo de micoplasmas genitais foi utilizado Kit Mycoplasma IST ${ }^{\circledR}$ (Bio-Mérieux), que faz diagnóstico por meio da identificação das espécies (controle/identificação de $M$. hominis e $U$. urealyticum), contagem de colônias ( $\geq 10^{4}$ CCU-Unidade de Mudança Colorimétrica) e antibiograma (doxiciclina, josamicina, ofloxacina, eritromicina, tetraciclina, pristinamicina).

Foi realizada, também, bacterioscopia pela coloração de Gram. Os resultados de todas as cul- 
turas e bacterioscopias foram informados ao corpo clínico.

O líquido amniótico remanescente foi encaminhado ao laboratório da MEAC/UFC para realização dos exames específicos para os quais havia sido indicado o procedimento.

Para análise estatística dos métodos diagnósticos usados para detecção da infecção assintomática do líquido amniótico utilizou-se o SPSS for Windows versão 7.0. Empregou-se o teste exato de Fischer para comparação do grupo de pacientes infectadas e não infectadas. Considerou-se haver significância estatística quando o resultado de $\mathrm{p}$ foi menor ou igual a 0,05.

\section{Resultados}

Foram colhidas 81 amostras de líquido amniótico de gestantes em várias idades gestacionais, variando entre a $14^{\mathrm{a}}$ e a $40^{\mathrm{a}}$ semana (média de 34 semanas), sem infecção clínica aparente. A idade materna média foi de 29,1 anos, a maioria era casada $(72,8 \%$ ) e $93,8 \%$ estavam em acompanhamento pré-natal.

Em apenas uma paciente foi colhido líquido amniótico na $14^{\mathrm{a}}$ semana, sendo o resultado negativo. A taxa de infecção assintomática do líquido amniótico foi maior entre grávidas que estavam entre a $24^{\mathrm{a}}$ e $32^{\mathrm{a}}$ semana $(22,2 \%)$. Na faixa compreendida entre a $33^{\mathrm{a}}$ e $40^{\mathrm{a}}$ semana o percentual de culturas positivas foi de $8,4 \%$ somente (Tabela 1). Essas diferença, entretanto, não foi significante $(p=0,22)$.

Tabela 1 - Presença de infecção do líquido amniótico em função da idade gestacional.

\begin{tabular}{lccrr}
\hline Infecção do & \multicolumn{3}{c}{ Idade Gestacional (semanas) } \\
Líquido Amniótico & \multicolumn{2}{c}{$\mathbf{2 4}$ a $\mathbf{3 2}$} & \multicolumn{2}{c}{$\mathbf{3 3}$ a $\mathbf{4 0}$} \\
& $\mathbf{n}$ & $\mathbf{\%}$ & $\mathbf{n}$ & $\mathbf{\%}$ \\
\hline Sim & 2 & 22,2 & 6 & 8,4 \\
Não & 7 & 77,8 & 65 & 91,6 \\
Total & 9 & 100,0 & 71 & 100,0
\end{tabular}

Teste exato de Fischer $-p=0,22$

Obs: Excluído da análise um caso coletado com 14 semanas.

Em oito pacientes $(9,8 \%)$ houve isolamento bacteriano no líquido amniótico (Tabela 2). Micoplasmas genitais foram isolados em todas as culturas positivas, sendo o Ureaplasma urealyticum evidenciado em sete casos e o Mycoplasma hominis em um. Peptostreptococcus sp foram identificados em dois casos, compreendendo $25 \%$ de invasão polibacteriana.
Tabela 2 - Espécies bacterianas isoladas nas culturas do líquido amniótico.

\begin{tabular}{lcc}
\hline Bactérias & $\mathbf{n}$ & $\%$ \\
\hline Ureaplasma urealyticum & 7 & 8,6 \\
Peptostreptococus sp & 2 & 2,4 \\
Mycoplasma hominis & 1 & 1,2 \\
Total & 10 & 12,3 \\
\hline
\end{tabular}

Pela coloração de Gram foram observados, em duas lâminas, cocos Gram positivos, identificados posteriormente, na cultura do líquido amniótico, como Peptostreptococcus sp. Nos casos em que se isolaram apenas micoplasmas a coloração de Gram foi negativa. A sensibilidade do Gram foi de 25\% (Tabela 3).

Tabela 3 - Índices diagnósticos da coloração de Gram na detecção da infecção assintomática do líquido amniótico.

\begin{tabular}{lc}
\hline & Coloração de Gram \\
\hline Sensibilidade & $25 \%$ \\
Especificidade & $100 \%$ \\
Valor de predição & $92,6 \%$ \\
Valor de predição positiva & $100 \%$ \\
Falso-positivos & - \\
Valor de predição negativa & $92,4 \%$ \\
Falso-negativos & $7,6 \%$ \\
\hline
\end{tabular}

Prevalência de 9,8\% de pacientes com infecção no líquido amniótico.

O padrão de resistência in vitro a antimicrobianos dos micoplasmas identificados caracterizou-se por maior resistência à eritromicina $(37,5 \%)$ e ausência de resistência às ciclinas. Nível intermediário foi verificado para josamicina, pristinamicina e ofloxacina $(12,2 \%)$. Não foram realizados antibiogramas para as bactérias anaeróbias estritas.

\section{Discussão}

A presença de microrganismos no líquido amniótico durante a gravidez é assunto de importância na prática clínica obstétrica. É citado ocorrer em $10 \%$ das grávidas com membranas intactas e em até $93 \%$ das pacientes com ruptura de membranas ${ }^{6}$.

A detecção pré-natal de microrganismos na cavidade amniótica capacita os obstetras a considerarem a administração dos antibióticos específicos, permitindo o tratamento adequado, diminuindo o risco do parto prematuro, a necessidade de tocólise e, em conseqüência, a mortalidade perinatal ${ }^{15}$. 
A idade gestacional parece estar associada com aumento do risco de infecção do líquido amniótico ${ }^{16}$. Minkoff et al. ${ }^{17}$ verificaram existir alto índice de infecção intra-uterina $(41,7 \%)$ em gestantes no $2^{\circ}$ trimestre. Vale ressaltar que, nesse estudo, os casos de morte neonatal ocorreram em prematuros que nasceram entre a $23^{a}$ e $25^{a}$ semana. Em nosso trabalho, houve elevado percentual de infecção assintomática em gestantes que estavam entre a $24^{\mathrm{a}}$ e $32^{\mathrm{a}}$ semana, as quais poderiam, segundo a literatura, estar mais sujeitas ao parto prematuro.

Romero et al. ${ }^{18}$ observaram que, em 41 gestantes com membranas intactas, 9,8\% apresentaram cultura do líquido amniótico positiva, percentual semelhante ao verificado em nossa pesquisa.

Um importante achado foi o alto índice de infecção intra-uterina assintomática por micoplasmas, em particular Ureaplasma urealyticum, seguido por Mycoplasma hominis e Peptostreptococcus sp. Romero et al. ${ }^{19}$ encontraram proporção de $42 \%$ de colonização cervical por Ureaplasma urealyticum, sugerindo que este pode ser um marcador adicional para o desenvolvimento de problemas adversos na gestação, desde que essas bactérias são constituintes da microbiota cérvico-vaginal e as condições imunológicas da gestante favoreceriam a sua proliferação.

Estudos microbiológicos do fluido amniótico que não incluem culturas para micoplasmas genitais, como a bacterioscopia pela coloração de Gram, podem subestimar a proporção de infecção intra-uterina. Estas bactérias estão associadas com elevados índices de infecção intrauterina, levando a perdas fetais ${ }^{17}$. A negatividade da pesquisa pelo Gram deve-se ao fato da ausência da parede celular nos micoplasmas. Por esse motivo, e pela presença freqüente desses microrganismos nos quadros infecciosos, como confirmado por nosso estudo, a pesquisa pela coloração de Gram não deve ser usada como método isolado para afastar infecção.

O tratamento da infecção intra-uterina, nestes casos, requer a adição de agentes que sejam ativos contra estas bactérias ${ }^{8}$. Mazor et al. ${ }^{20}$ demonstraram que a erradicação dos micoplasmas da cavidade amniótica contribui significativamente para o prolongamento da gestação e sobrevivência neonatal sem seqüelas patológicas.

Os antibióticos de escolha contra micoplasmas genitais são as tetraciclinas e doxiciclina e as cepas testadas in vitro não apresentaram resistência contra estes antimicrobianos. Esses, no entanto, especialmente as tetraciclinas, não podem ser utilizados em gestantes ${ }^{20}$. Nesses casos, o antibiótico de escolha seria a eritromicina, porque pode ser usada seguramente na gravidez e o
pH neutro do líquido amniótico favoreceria sua ação, embora não erradique micoplasmas da região cervical. Entretanto, em nosso trabalho, observamos que $37,5 \%$ das cepas eram resistentes in vitro a este antibiótico, porcentagem bem menor que o observado por Kudsin et al. ${ }^{21}$. Estes autores observaram que $86 \%$ das cepas de Ureaplasma isoladas eram resistentes à eritromicina. Novas alternativas terapêuticas, seguras na gestação, devem ser testadas, maximizando o tratamento efetivo dos quadros infecciosos.

Desde que os micoplasmas estiveram presentes na totalidade das culturas positivas do líquido amniótico, há necessidade de explorar a relação entre infecção intra-uterina assintomática e estas bactérias. Talvez com isso possamos reduzir a morbidade e mortalidade perinatais por meio do diagnóstico imediato e da administração de quimioterápicos apropriados. O grande dilema, entretanto, é definir, em pacientes assintomáticas do ponto de vista infeccioso, com quase $10 \%$ de infecção intra-útero, quais grávidas deverão ser pesquisadas e tratadas. Novas pesquisas tornamse necessárias para definição de outros fatores, que não a amniorexe prematura ou o trabalho parto prematuro, que possam estar vinculados à infecção subclínica.

\section{ABSTRACT}

Purpose: to determine the presence of asymptomatic amniotic fluid infection in pregnant women, to identify the bacterial agents involved in the infection and to determine the antimicrobial susceptibility in vitro.

Methods: amniotic fluid samples were obtained by amniocentesis from 81 pregnant women without labor signs and without suspucion of clinical infection, attended at Maternidade Escola Assis Chateaubriand from August 1997 to January 1999. The presence of aerobic bacteria, strict/ facultative anaerobic bacteria and genital mycoplasmas was investigated. The anaerobic bacteria were identified by the ATB System ${ }^{\circledR}$ (Biolab Mérieux) and mycoplasmas by the IST Mycoplasma ${ }^{\circledR}$ kit (Biolab-Mérieux).

Results: among the obtained samples, eight (9.8\%) showed positive culture and in two samples two different strains were identified. The isolated pathogens were Ureaplasma urealyticum (7 cases, 8.6\%), Mycoplasma hominis (1 case, $1.2 \%)$ and Peptostreptococcus $s p$ (2 cases, 2.4\%). The antimicrobial susceptibility was characterized by great mycoplasma resistance to erythromycin (37.5\%) and no resistance to cyclins.

Conclusions: the percentage of asymptomatic infections was high, and furthe research is necessary to evaluate the asymptomatic infection consequences in pregnant women and their newborns, involving methods that identify genital 
mycoplasmas, which were the most frequently isolated bacteria.

KEY WORDS: Amniotic fluid. Chorioamnionitis. Infections in pregnancy.

\section{Referências}

1. Andrews WW, Hauth JC, Goldenberg RL, Gomez R, Romero R, Cassell GH. Amniotic fluid interleukin-6: correlation with upper genital tract microbial colonization and gestational age in women delivered after spontaneous labor versus indicated delivery. Am J Obstet Gynecol 1995; 173:606-12.

2. Wallace RL, Herrick CN. Amniocentesis in the evaluation of premature labor. Obstet Gynecol $1981 ; 57: 483-6$.

3. McDonald HM, O'Loughlin, Jolley PT, Vigneswaran $\mathrm{R}$, McDonald PJ. Changes in vaginal flora during pregnancy and association with preterm birth. J Infect Dis 1994; 170:724-8.

4. McGregor JA, French JI, Richter R, et al. Antenatal microbiologic and maternal risk factors associated with prematurity. Am J Obstet Gynecol 1990; 163:1465-73.

5. Gravett MG, Hummel D, Eschenbach DA, Holmes KK. Preterm labor associated with subclinical amniotic fluid infection and with bacterial vaginosis. Obstet Gynecol 1986; 67:229-37.

6. Galask RP, Varner MW, Petzold CR, Wilbur SL. Bacterial attachment to chorioamniotic membranes. Am J Obstet Gynecol 1984; 148:91528.

7. Romero R, Mazor M. Infection and preterm labor. Clin Obstet Gynecol 1988; 31:553-84.

8. Bobitt JR, Hayslip CC, Damato JD. Amniotic fluid infection as determined by transabdominal amniocentesis in patients with intact membranes in premature labor. Am J Obstet Gynecol 1981; 140:947-52.

9. Garite TJ, Freeman RK, Linzey EM, Braly P. The use of amniocentesis in patients with premature rupture of membranes. Obstet Gynecol 1979; 54:226-30.

10.Romero R, Sirtori M, Oyarzun E, et al. Infection and labor. V. Prevalence, microbiology, and clinical significance of intraamniotic infection in women with preterm labor and intact membranes. Am J Obstet Gynecol 1989; 161:817-24.
11.Romero R, Ghidini A, Mazor M, Behnke E. Microbial invasion of the amniotic cavity in premature rupture of membranes. Clin Obstet Gynecol $1991 ; 34: 769-78$.

12.Romero R, Salafia CM, Athanassiadis AP, et al. The relationship between acute inflammatory lesions of the preterm placenta and amniotic fluid microbiology. Am J Obstet Gynecol 1992; 166:1382-8.

13.Polzin WJ, Brady K. Mechanical factors in the etiology of premature rupture of the membranes. Clin Obstet Gynecol 1991; 34:702-14.

14.Koneman EW, Allen DA, Dowell VR, Sommers HM. Color atlas and textbook of diagnostic microbiology. $1^{\text {st }}$ ed. Philadelphia: JB Lippincott; 1992. p.675-701.

15.Quinn PA, Butany J, Chipman M, Taylor J, Hannah W. Prospective study of microbial infection in stillbirths and early neonatal death. Am J Obstet Gynecol 1985; 151:238-49.

16. Horowitz S, Mazor M, Romero R, Horowitz J, Gleserman M. Infection of the amniotic cavity with Ureaplasma urealyticum in the midtrimester of pregnancy. J Reprod Med 1995; 40:375-9.

17. Minkoff H, Grunebaum AN, Schwarz RH, et al. Risk factors for prematurity and premature rupture of membranes: a prospective study of the vaginal flora in pregnancy. Am J Obstet Gynecol 1984; 150:965-72.

18.Romero R, Emamian M, Quintero R, et al. The value and limitations of the Gram stain examination in the diagnosis of intraamniotic infection. Am J Obstet Gynecol 1988; 159:114-9.

19.Romero R, Yoon BH, Mazor M, et al. A comparative study of the diagnostic performance of amniotic fluid glucose, white blood cell count, interleukin6 and Gram stain in the detection of microbial invasion in patients with preterm premature rupture of membranes. Am J Obstet Gynecol 1993; 169:839-51.

20.Mazor M, Chaim W, Horowitz S, Leirberman JR, Glezerman M. Successful treatment of premature labour by eradication of Ureaplasma urealyticum with erythromycin. Arch Gynecol Obstet 1993; 253:215-8.

21.Kudsin RB, Horne HW, Walter CW. Ureaplasma urealyticum resistance to erythromycin: confirmed by medical trial [letter]. Am J Obstet Gynecol 1992; 166:1864. 